\title{
A Study on the Effects of Fiber Orientation on Woven Glass Fiber Composite Structures
}

\author{
Rokesh Laishram $^{1 *}$, Bisheshwar H. ${ }^{2}$ Shivakumar N.D. ${ }^{3}$, Bharadwaj Amrutur ${ }^{1}$ and T.Y. Reddy \\ ${ }^{1}$ Robert Bosch Centre for Cyber-Physical Systems, Indian Institute of Science, Bangalore-560012. \\ ${ }^{2}$ National Institute of Design, Jorhat-785014, India \\ ${ }^{3}$ Center for Product Design and Manufacturing, Indian Institute of Science, Bangalore-560012, India \\ ${ }^{3}$ Vemana Institute of Technology, Bangalore-560034, India \\ *Corresponding Author: Email: - laishrams@iisc.ac.in
}

\begin{abstract}
.
Scholars have studied hybrid composites for decades in the search of finding some good outcome which could be used for different purposes. The present study is focused on studying the effects of fiber orientation through mechanical testing on coupons made according to ASTM standards and through dropped weight test on tubes made of the same configuration. Initially, the tensile experiments of laminas; normal [0/90] and oriented [+45/45] are conducted as a preliminary study and a distinctive behaviour could be seen. The oriented one shows low tensile strength and low modulus but very high failure strains while the other one having high tensile strength and modulus but low failure strain. In the laminate of 3 plies $\left[(0 / 90)_{3}\right]$ and $[(0 / 90) /(+45 /-45) /(0 / 90)]$, upon comparing the results, it is found that the tensile and compressive stress-strain results are almost similar but the shear experimental result shows some interesting behaviour due to the addition of a (+45/-45)ply in the middle of the later laminate. Axial Dropped weight tests on circular tubes made of the same configuration are also conducted for comparing the energy absorption characteristics and failure behaviours.
\end{abstract}

Keywords: Glass/polyester composites, impact crushing, mechanical testing. 


\section{Introduction}

The behaviour of tubular structures like square tubes (Reid, 1993), circular tubes (Reid, 1993), hat section (A.Deb, B.Haorongbam, \& N.K.Gupta, 2013), etc. made of metals and composites (A.Deb A. s., 2013) used in automobiles under quasistatic and impact loading has been a major area of study in academic as well as in industries as an energy absorber. (Reid, 1993) reviewed the characteristics of several metal components which are used as energy absorber with focus on the mode of deformation. Progressive buckling (Reid, 1993), inversion (Reid, 1993) and splitting are major areas of deformation in metal while for composite (Songi, Wan, \& Du, 2000) fragmentation; delamination and catastrophic failure are major modes of failure. (Deb, Das, Mache, \& Laishram, 2017) studied a special case of hybrid-composite to reduce catastrophic failure and enhance mechanical properties. Tubular structures filled with polyurethane foam as energy absorber may also be mention (Haorongbam \& T.Y.Reddy., 2017) (Zhou, Guan, \& Cantwell, 2018). A combination of steel and carbon fiber-reinforced polymer was studied to see the benefit of the stable, ductile plastic collapse mechanism of steel and the high strength to weight ratio of fiber/resin composite and found that it improves in both load uniformity and specific energy absorption (MR, Elchalankani, \& Zhao, 2009).Berry studied the effect of the different hoop to axial ratios in which the warp and weft directions were parallel to the hoop and axial directions (Berry J, 1984). The study on different thickness by diameter was done by (Hamada \& Ramakrishna, 1995) and found out that the specific energy absorption depends on the absolute value of thickness rather than $t / D$ and also it increases with increase in thickness up to a certain value ( 2 to $3 \mathrm{~mm}$ has highest) after that, it decreases. The triggering technique has also some effect on the energy absorption capability of the tube (Palanivelu, et al., 2010) and its numerical study (Plalnivelu, et al., 2009). Impact load direction also plays an important role in energy absorption and it varies with the angle of impact (Paruka, Shah, \& Mannan, 2013). The investigation done on carbon/peek tubes with different fiber angles in (Hamad \& Ramakrisha, 1990) (Mahdi \& sebaey, 2014) concluded with [+15/-15] orientation being the highest energy absorber. In most of the studies, the fiber at 0/90 degree has higher capacity than oriented in different angles like [+55/-55] (D.Hull, 1991) (Hull, 1982) and [+45/-45] (H \& Edwards, 1982) (Berry J, 1984). Some of the studies show that different materials have different variation in energy absorption capacity. In the case of glass/polyester composites, the energy absorption increases from [+35/-35] up-to [+65/-65] and started reducing till 90-degrees (R, 1983). (GI, 1987) Found that carbon epoxy decreases with increasing angle till 45-degree and remain constant while glass epoxy and Kevlar remain constant up-to 45-degree and increases with increase in orientation angle. Some of the explanations given are reduction in axial stiffness in carbonepoxy with increasing angle and for glass epoxy and Kevlar epoxy has the support of fiber in the lateral direction. The effect of the fiber orientations studied in (Hu, Zhang, Ma, \& Song, 2016) concluded that the orientation of the fiber on composite structures has a larger effect on the energy absorbing performance. Most of the work on fiber orientation is done on filamentwound unidirectional fiber (J, Kumosa, \& Hull, 1991) (Kim, Yoon, \& Shin, 2011) and less on woven fiber (Berry J, 1984) (Kim, Yoon, \& Shin, 2011) but the study on mixing 
of woven ply to make component has no record till now. The review done in (Supian, Sapuan, MYM, \& YA, 2018) (Swolfs, Gorbatikh, \& verpoest, 2014) concludes that hybridization proves positive in many of the cases.

Two cases have been studied where case 1 configuration is [0/0/0] has fiber weaved in [0/90] degree and case 2 is [0/45/0] Fig 1 has fiber cut in [+45/-45]. The case of [0/45/0] tube has not been studied anywhere and the study is focused on this.

\section{Experimentation}

\subsection{Materials and fabrication}

Woven roving glass fiber of $360 \mathrm{gsm}$ and polyester resin were used for fabrication with compression assisted hand layup technique. The laminates are fabricated using compression assisted hand layup technique in which the fiber ply and resin is sandwiched between two smooth thick metal sheets upon which high presser is applied. The extra resins are spread out due to the pressure. To maintain a certain thickness spacer of desire thickness are used at the side of the metal sheets to limit the compression. Laminate configuration Fig:-1 and fabricated tube Fig 2 is shown below:-. PVC tubes of outer diameter $40 \mathrm{~mm}$ are taken as mould for making the circular tubes. Mylar sheets are used for glassy finished. A circular PVC tube of outer diameter is used as a mould. The tubes are then cut at a length of $150 \mathrm{~mm}$ with an inner diameter of $40 \mathrm{~mm}$. There is a slight difference in the mass as more resins are required to make the case 2 tube and were fabricated to experimental level after a certain trial and error. The end part of the first roll of fiber will be the starting point of the next ply.

Figure 1: Fiber Orientation for Case 2 [0/45/0]

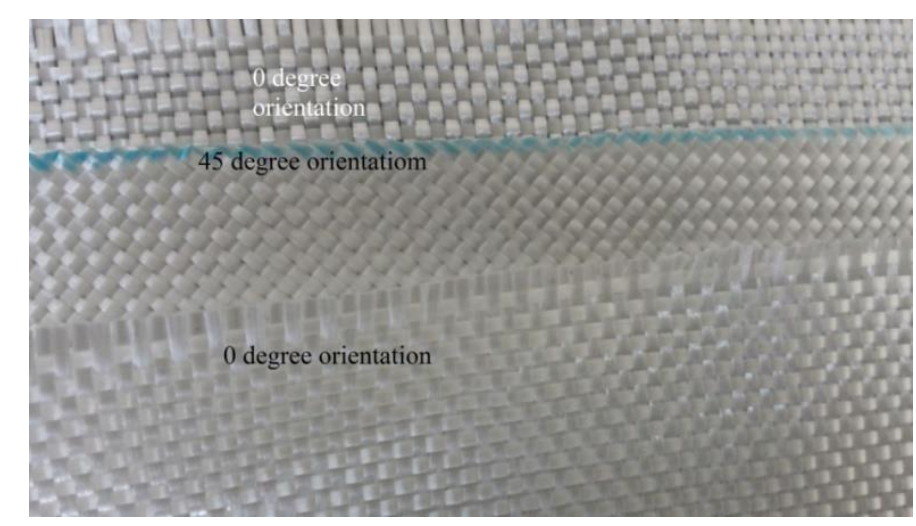

The tubes have been chamfered Fig. 2 at the top to make the tube progressively fail and avoid catastrophic failure. 
Figure 2: Tube for Impact Test (Chamfered Tip of the Tube)

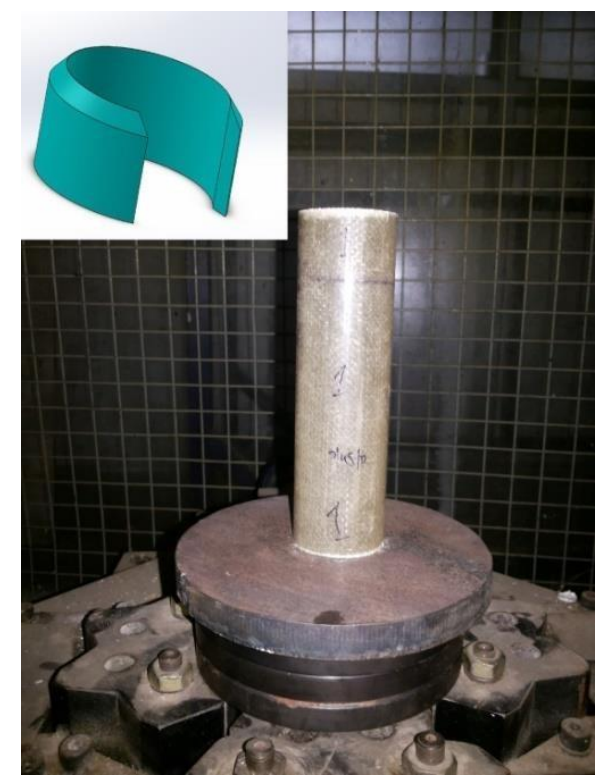

\subsection{Coupon Test}

Tensile experiments were conducted on the coupon extracted from the laminate using ASTM standard (D3039/D3039M-08, 2017) while compression using ASTM standard (D3410/D3410M-08, 2016). The experiments were carried out using a $100 \mathrm{KN}$ Universal Testing Machine at a speed of $1 \mathrm{~mm}$ per minute to quantify the tensile strength, tensile stiffness, compression strength, and shear strength (Venkatesh, 2012).

Picture of the experiments is shown in Fig 4, Fig 5 and Fig 6. In the case of the tensile test, the extensometer is used at the center of the specimen with a gauge length of $25 \mathrm{~mm}$ to measure the stiffness more accurately. Since composite materials show brittle failure behaviors the extensometer is set to be removed at $1.5 \%$ of the gauge length. The sudden drop in the tensile graph shows the removal of the extensometer. However, in the case of the lamina, the extensometer is not used as it might damage the specimen as the specimen is very thin. In case of compression, the experiments are not carried out with laminas because for thin specimens the gauge length should be very small otherwise the specimen will start buckling instead of taking the load. In the case of shear test, the tensile load is applied and the specimen is cut in such a way that when a pull force is applied to the specimen the material in the center feels a shear force as shown in the Fig 7. 
Figure 3: Left Tensile Experiment with Extensometer and (right) Compression Experiment (with Failed Specimens)
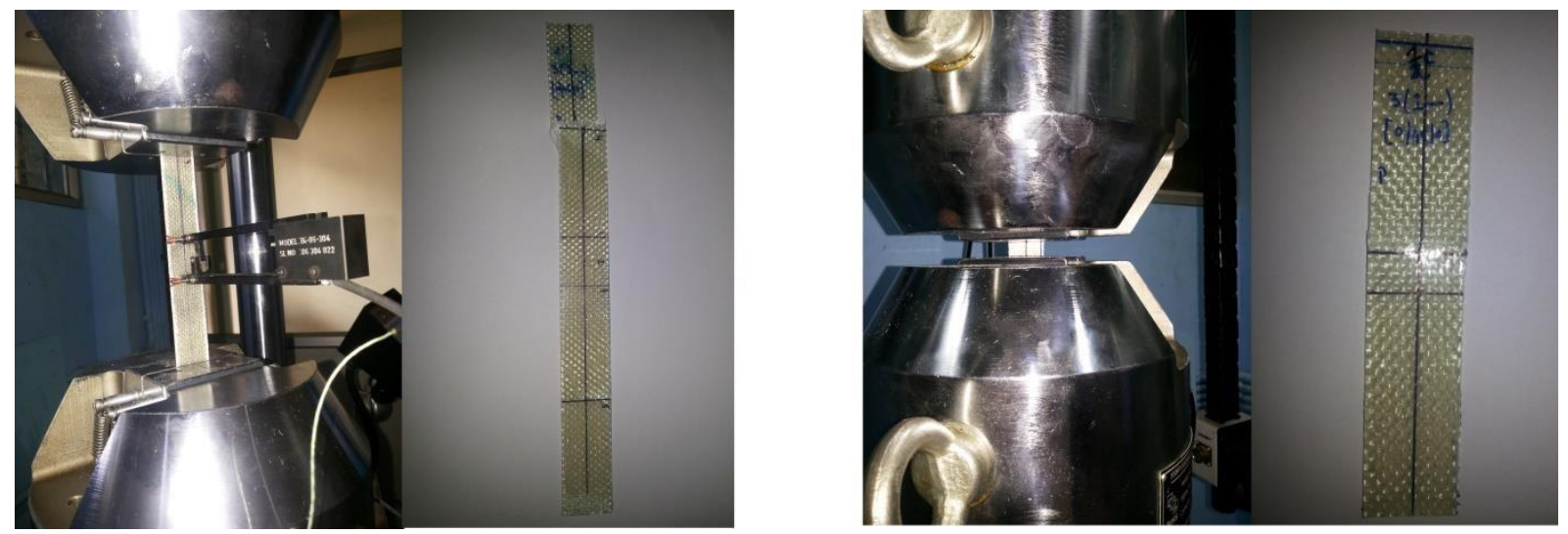

Figure 4: Shear Experiment with Failed Specimen (Specimen Specification)
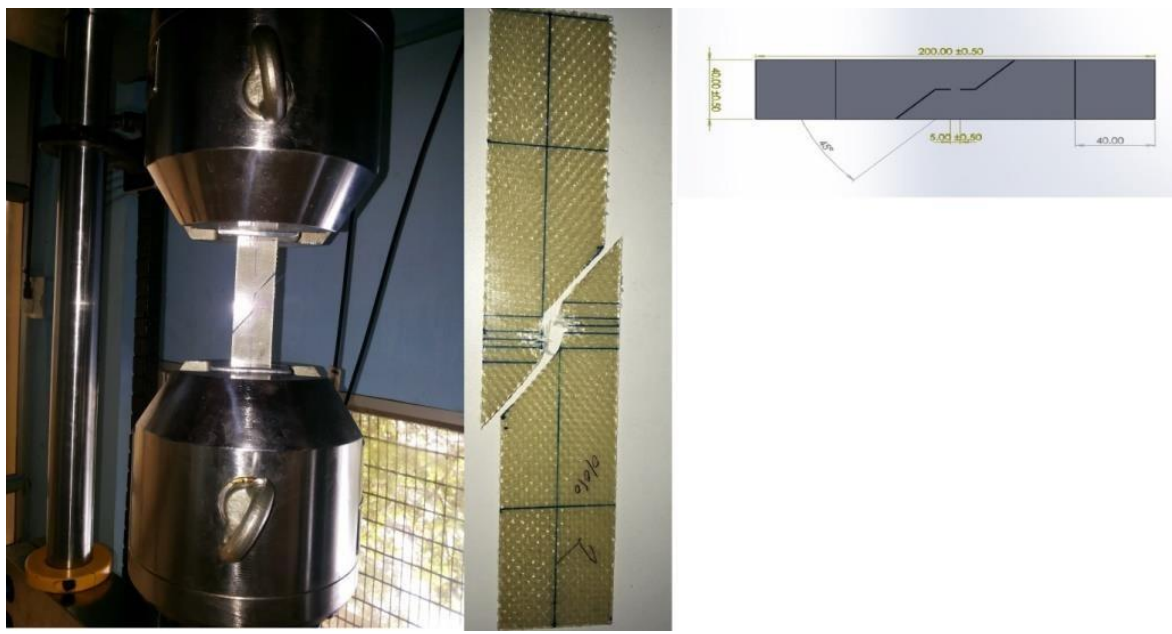

\subsection{Dropped Weight Test}

The experiment for low-velocity impact is done on a set up called "DWITT" (Dropped Weight Instrumented Testing Tower) Fig 8 in which a weight is dropped from a certain height over the object or specimen. Keeping the specimen at the base of the DWITT the weightbearing $134 \mathrm{~kg}$ is dropped from a height of 0.45 meters the potential energy is converted in kinetic energy which is later absorbed by the specimen kept at the base.

To compare the performance of materials and component geometry the specific crushing stress is the most useful and distinctive parameter and a large variation of crushing stress can 
be achieved by varying or controlling the fiber geometry. Crushing initiates in the high stressed region at the tip of the chamfer and this develops into a stable crushed zone.

Figure 5: Drop Weight Experimental Set Up

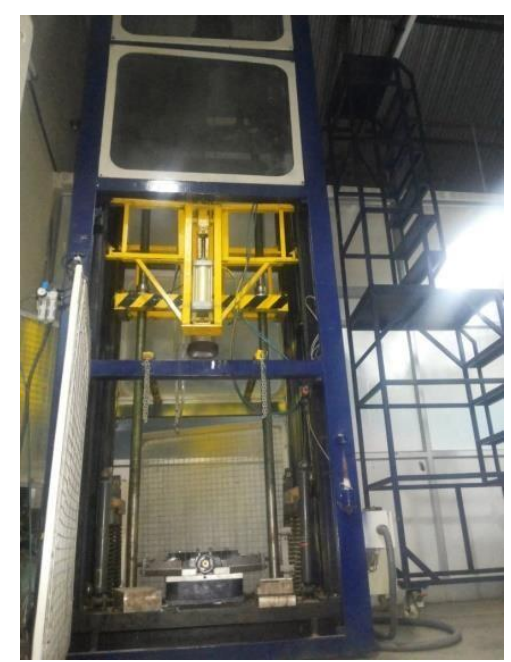

The initial slope of load-displacement is less in chamfer than square end because crushing starts at the chamfer part. Hoop ring shraded off and fail in tension (outer) and compression inner. Fragmentation and spaying mode are the two major failures. Hoop to axial ratio (H: A) is the amount of fiber in hoop direction and axial direction (more axial fiber more peak load for axial load) [8]. The main factors which affect the crush behavior are fiber, matrix, crushing speed and temperature.

Figure 6: Failed Tube After Weight Dropped

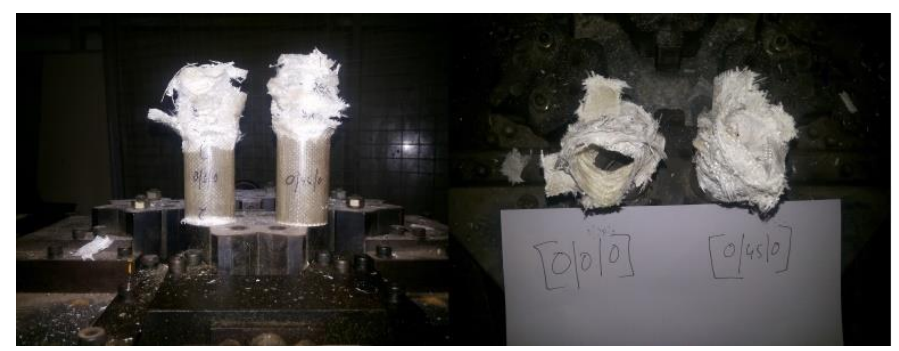

Majority of the load is carried by the axial fiber because the modulus is higher in that direction. The fiber in the hoop direction supports the axial fiber and minimizes premature buckling. The axial fiber has splayed in a series of fronds to the outside and inside of the tube. A wedge of debris, consisting of crushed fibers and resin, forms at the surface of the crushing platen at an early stage in the crushing process. As the axial fibers splay outwards the external hoop fibers are subjected to tension and eventually fracture. The axial fibers splay inwards the 
internal hoop fibers are compressed and the layer fails by buckling and intra-laminar shear normal to the fibers (the shear strength has a very high modulus in case 2).

Crushed tubes with debris compacted inside preventing further crushing. When viscosity or plastic deformation occurs at the crush zone the load-displacement curves are less sharply serrated.The hoop fiber prevents the splaying of the tube so the fiber in the middle ply of the case 2 tube increases the number of fibers in the hoop direction which can be seen in the figure.A series of axial cracks have formed around the circumference of the tube which is

approximately equally spaced. The cracking is caused by the expansion to the outer layers and involves both fiber fracture and tensile fracture transverse to the fibers. The fiber in the hoop direction prevents or reduces the splaying of the axially oriented fibers. The cloth layers delaminated but intact and when the load is removed they sprang back as a bundle of sheets. The splaying is more in case 1.In case 2 the hoop fiber increases and the axial fiber decreases which might result in decreasing the axial reaction load but splaying will be reduced and the required load to causing fragmentation will also increase. The splaying phenomenon also occurs in tubes when forced into a die of $10 \mathrm{~mm}$ radius and is also known as axial splitting [5]. The debris for case two is larger which shows that the material got fractured with less deformation.The Hoop to Axial ratio in both the cases is 1:1 but case two has less number of fibers as the middle ply is inclined at 45 degrees. The debris for case two is larger which shows that the material got fractured with less deformation.

\section{Results}

Figure 7: Graphical Representation of Tensile Experiment

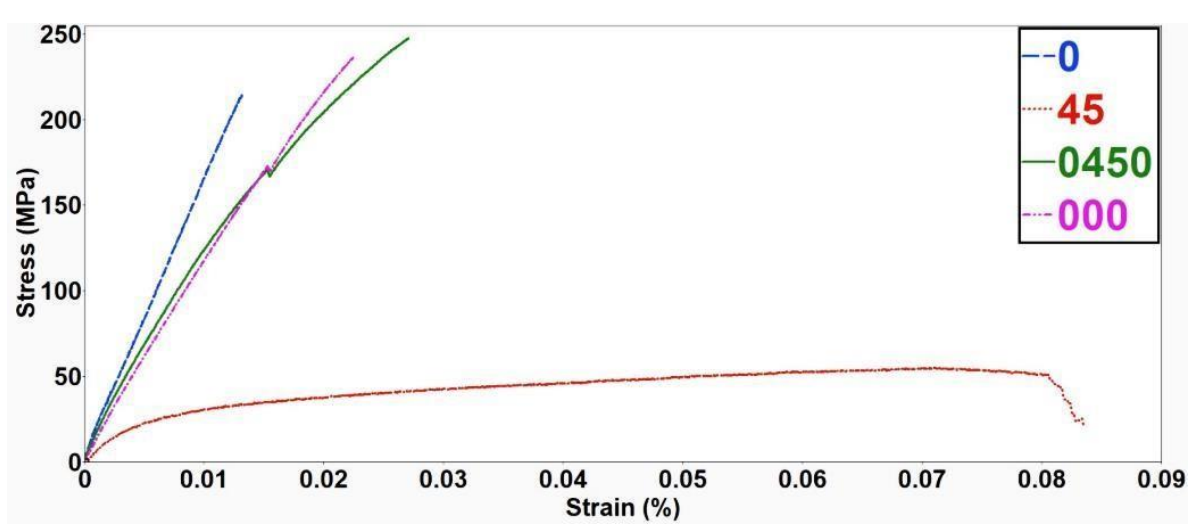

Figure 8: Graphical Representation of Compression Experiment 


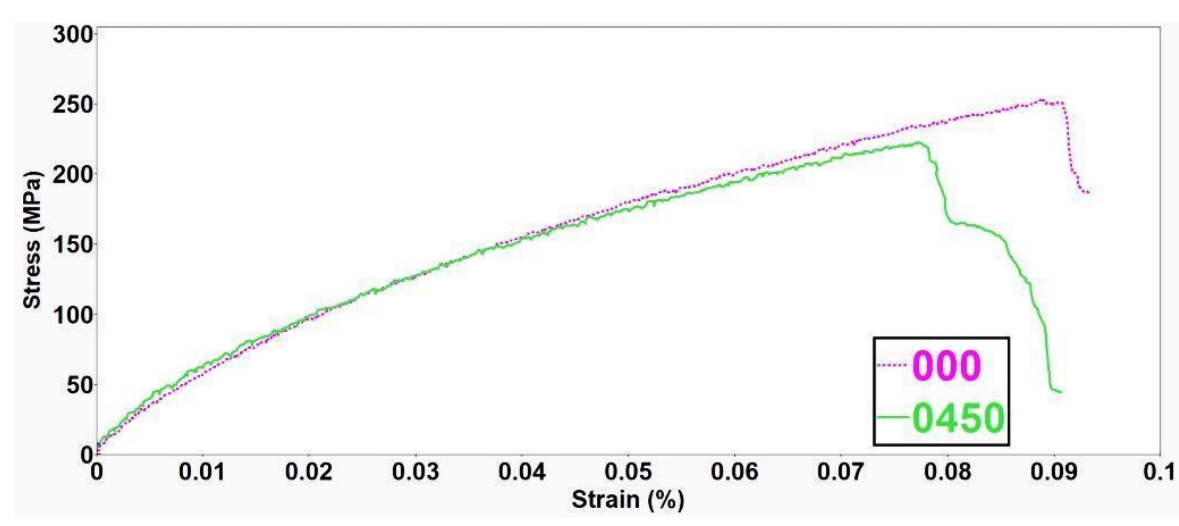

Figure 9: Graphical Representation of Shear Experiment

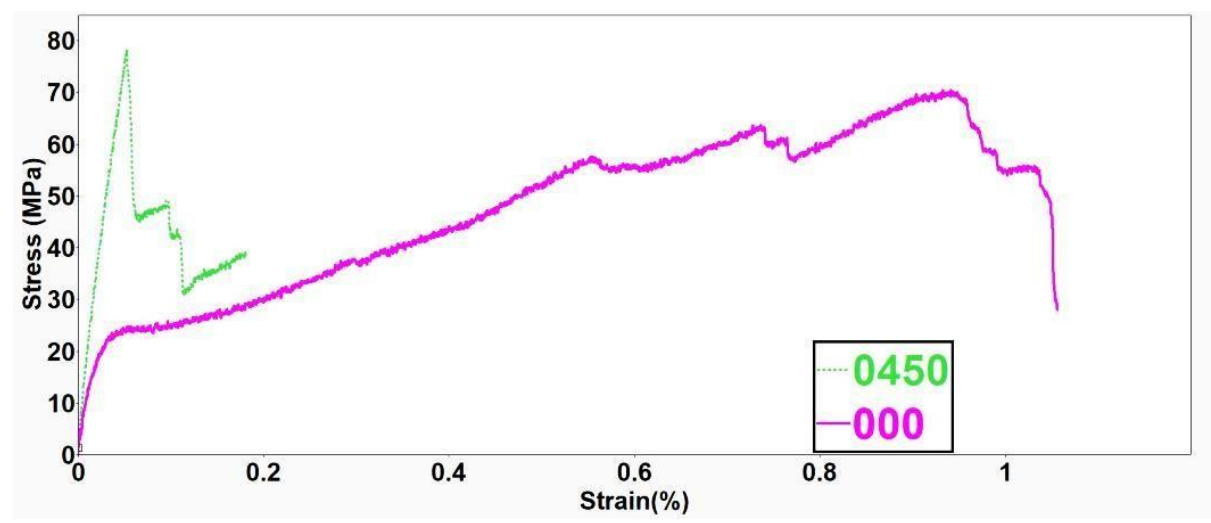

Table 1: Comparison of Tensile, Compression and Shear Experimental Results on Coupon

\begin{tabular}{|c|c|c|c|c|c|c|c|}
\hline \multirow[t]{2}{*}{ Case } & \multirow{2}{*}{$\begin{array}{c}\text { Thickness } \\
\text { (mm) }\end{array}$} & \multirow{2}{*}{$\begin{array}{c}\text { Fiber } \\
\text { Volume } \\
\text { Fraction }\end{array}$} & \multirow{2}{*}{$\begin{array}{l}\text { Tensile } \\
\text { Modulus } \\
(\mathrm{GPa})\end{array}$} & \multirow{2}{*}{$\begin{array}{c}\text { Tensile } \\
\text { Strength } \\
(\mathrm{MPa})\end{array}$} & \multirow{2}{*}{$\begin{array}{l}\text { Compression } \\
\text { Strength }(\mathrm{MPa})\end{array}$} & \multicolumn{2}{|c|}{ Shear strength $(\mathrm{MPa})$} \\
\hline & & & & & & $\begin{array}{l}\text { Initial } \\
\text { Peak }\end{array}$ & $\begin{array}{l}\text { Final } \\
\text { Peak }\end{array}$ \\
\hline$[0]$ & 0.4 & $35 \%$ & 16 & 213 & - & - & - \\
\hline$[45]$ & 0.4 & $35 \%$ & 5 & 55 & - & - & - \\
\hline$[0 / 45 / 0]$ & 0.95 & $42 \%$ & 12.39 & 247.46 & 222.52 & 74.6 & 74.6 \\
\hline
\end{tabular}




\begin{tabular}{|l|l|l|l|l|l|l|l|}
\hline$[0 / 0 / 0]$ & 0.95 & $42 \%$ & 11.71 & 236.79 & 252.88 & 26.94 & 66.48 \\
\hline
\end{tabular}

The increase in the stiffness at the initial stage could be seen in the [0/45/0] coupon test of tensile and the strain increases as the load is being applied while its starts buckling at an early stage compared to the normal [0/0/0] which results in the less compressive strength.

Figure 10: Load displacement curve for tubes

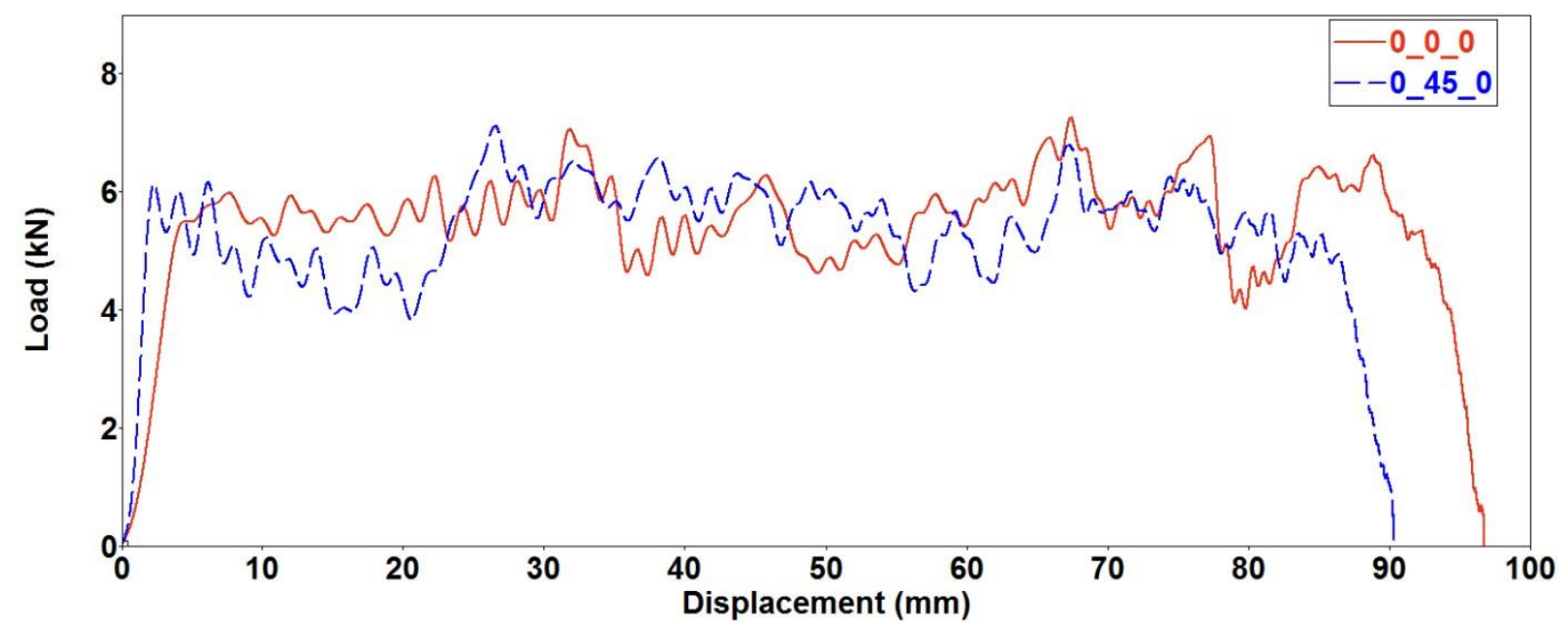

The area under the load-displacement graph gives the energy absorbed. The crossed ply tube has less crushed length when the same weight is dropped from the same height. The fragments of the composite with [0/0/0] were more continuous while that of $[0 / 45 / 0]$ was like chopped into smaller pieces

Table 2: Comparison of Dropped Weight Experimental Results on Tubes

\begin{tabular}{|l|l|l|l|l|l|l|l|l|}
\hline Case & $\begin{array}{l}\text { Thickness } \\
(\mathrm{mm})\end{array}$ & $\begin{array}{l}\text { Energy } \\
\text { Absorbe } \\
\mathrm{d} \\
\text { (joules) }\end{array}$ & $\begin{array}{l}\text { Crushed } \\
\text { length } \\
(\mathrm{mm})\end{array}$ & $\begin{array}{l}\text { Peak } \\
\text { Load } \\
(\mathrm{KN})\end{array}$ & $\begin{array}{l}\text { Mean } \\
\text { Load } \\
(\mathrm{KN})\end{array}$ & $\begin{array}{l}\text { Mass } \\
\text { before } \\
\text { Experiment }\end{array}$ & $\begin{array}{l}\text { Crushed } \\
\text { Mass }\end{array}$ & $\begin{array}{l}\text { Specific } \\
\text { Energy } \\
\text { Absorbed } \\
\text { joules/ } \\
\text { gram) }\end{array}$ \\
\hline$[0 / 45 / 0]$ & 1.3 & 476.5 & 90.3 & 7 & 5.28 & 40 & 24.19 & 19.70 \\
\hline$[0 / 0 / 0]$ & 1.2 & 524.43 & 96.73 & 7.2 & 5.42 & 36 & 23.21 & 22.6 \\
\hline
\end{tabular}

\section{Discussion}


The study shows that little resistant to the load is offered when a crossed ply in between is hybridized. Due to the use of only a single ply larger effect couldn't be seen but certain change in the tensile and compression graph are encountered during experiments as well as in the tube crushed. Manufacturing of circular tubes with such configuration has many difficulties. Due to that more resins used to stick the fiber plies which results in more resin weight. A clearer picture of the results of hybridized fiber plies could be seen in components like hat sections (single and double) where the end part of a ply needn't be the starting part of other ply. In a circular tube the continuation becomes a problem from a ply to another. The configuration can be used for offset impact on tubes as the number of fiber will be more. The tubes whose fiber oriented at different angle has low peak load when impacted or loaded from axial direction. Studies can be conducted (axial as well as lateral loading) on different configuration by increasing the number plies in each orientation like $0 / 0 / 45 / 45 / 0 / 0$, 45/45/0/0/45/45 etc. Circular tubes, square tubes, honey comb tubes will be difficult to manufacture or fabricate compare to hat sections and half hat sections.

Unlike unidirectional tube the splaying of the fiber is less but could be seen more in case 1 than case 2 .

\section{Acknowledgement}

The authors would like to thank Dr. Anindya Deb for providing facilities to fabricate the specimens and conduct the experiment of the same. The authors would also like to give special thanks to Late Dr. H.V. Lakshminarayan for his constant support during the work.

\section{Appendix}

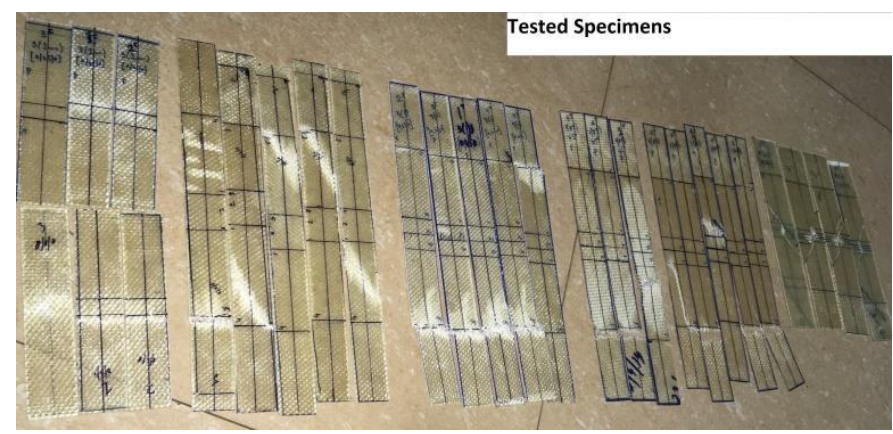




\section{References}

[1] A.Deb, A. s. (2013). A Comparative Study on the Axial Impact Performance of Jute and Glass Fiber-Based Composite Tubes. SAE Technical Paper2013-01-1178.

[2] A.Deb, B.Haorongbam, \& N.K.Gupta. (2013). Thin-walled steel hat section components as protective counter - measures for vehicle impact. Proc Indian Natn Sci Acad, 669-678.

[3] Berry J, P. (1984). Energy absorption and failure mechanism of axially crushed wound tubes. Liverpool.

[4] D.Hull. (1991). A unified approach to progressive crushing of fiber reinforced composite tubes. Composite Science and Technology, 40, 377-421.

[5] D3039/D3039M-08, A. (2017). Standard test Method for Tensile Prperties of Polymer Matrix Composite Materials. ASTM International.

[6] D3410/D3410M-08, A. (2016). Standard Test Method for Compressive Properties of Polymer Matrix Composite Materials with Unsupported Gage Section by Shear Loading. ASTM International.

[7] Deb, A., Das, S., Mache, A., \& Laishram, R. (2017). A study on the mechanical behaviors of jute- polyester composites. Procedia Engineering, 631-638.

[8] GI, F. (1987). Energy Absorption Capability of Composite Materials and Structures. 43rd American Helicopter Society Annual forum, 613-627.

[9] H, T. P., \& Edwards, P. J. (1982). Energy Absorption of Composite Tubes. Journal of Composite Materials, 16, 521-545.

[10] Hamad, H., \& Ramakrisha, S. (1990). Effect of Fiber Orientation on Eenergy Absorption Capability of Carbon Fiber Peek Composite Tube. Journal of Composite Material, 947-963.

[11] Hamada, H., \& Ramakrishna, S. (1995). Scaling Effect in the Energy Absorbtion of Carbopn Fiber/Peek Composite. Composite Science and Technology, 55, 211-221.

[12] Haorongbam, B.,A,Deb \& T.Y.Reddy.,. (2017). Numerical prediction of polyurethane foam filled steel hat Section tubes under axial loading. IJIRAE, 4(4).

[13] Hu, d., Zhang, C., Ma, X., \& Song, B. (2016). Effect of Fiber Orientation on the Energy Absorption Characterstics of Glass Cloth/Epoxy Composite tubes Under Axial quasistatic and Impact Crushing Condition. Composites: Part A, 90, 489-501.

[14] Hull, D. (1982). Energy Absorption of Composite under Crash Conditions. ICCM-IV, 861-870.

[15] J, S., Kumosa, M., \& Hull, D. (1991). Trigger mechanism in Energy Absorbing Glass cloth/Epoxy Tubes. Composite Science and Technology, 40, 265-287.

[16] Kim, j. S., Yoon, H. J., \& Shin, K. B. (2011). A Study on Crushing Behaviors of Composite Circular Tubes with Different Reinforcing Finers. International Journal of Impact Engineering, 198-207. 
[17] Mahdi, E., \& sebaey, A. h. (2014). The Effect of Fiber Orientation on the Energy Absorption Capability of Aially Crushed Composite Tubes. Materials and Design, 56, 932928.

[18] MR, B., Elchalankani, M., \& Zhao, X. (2009). Composite Steel-CFRP SHS tubes Under Axial Impact. Composite Structures, 87, 282-292.

[19] Palanivelu, S., Paepegem, W. P., Ackeren, J. V., Kakogiannis, D., Hemelrijck, D. V., Wastiel, J., et al. (2010). Experimental Study on the Axial Crushing Behavior of Plutruded Composite Tubes. Polymer Testing, 29, 224-234.

[20] Paruka, P., Shah, M. K., \& Mannan, M. A. (2013). Influence of Axial and Oblique Impact Loads on Crush Response Properties of Square Tube Structure made with FRP Pultruded Composite. Procedia Engineering, 68, 572-578.

[21] Plalnivelu, S., Paepegem, W. V., Degrieeck, J., Kakogiannis, D., Ackeren, J. V., Hemelrijck, D. V., et al. (2009). Numerical Energy Absorption Study of Composite Tubes for Axial Impact Loadings. Composite Materials, 17th International Conference.

[22] R, K. (1983). Post Failure Energy Absorbing Mechanism of filament Wound Composite Tubes. Liverpool: University of Liverpool,UK.

[23] Reid, S. (1993). Plastic Deformation Mechanism is axially compressed metal tubes used as impact energy absorbers. IJMS, 35, 1035-1052.

[24] Songi, H.-W., Wan, Z.-M., \& Du, Z.-M. X.-w. (2000). Axial impact behavior and energy absorption efficiency of composite wrapped metal tubes. International Journal of Impact Engineering, 35, 385-401.

[25] Supian, A., Sapuan, S., MYM, Z., \& YA, H. (2018). Hybrid Reinforced Thermoset Polymer Composite in Energy Absorption Tube Application: A Review. Defence Technology, 14, 291-305.

[26] Swolfs, Y., Gorbatikh, L., \& verpoest, I. (2014). Fiber Hybridisation in Polymer Composite: A Review. Composites: Part A, 67, 181-200.

[27] Venkatesh, G. (2012). An Exploration of natural and Polymer based Composite for Advanced Engineering Design. Indian Institute of Science.

[28] Zhou, J., Guan, Z., \& Cantwell, W. (2018). The Energy Absorbing Behavior of Composite Tube-Reinforced Foams. Composite Part B, 139, 227-237. 